06

\title{
Фотолюминесценция низкоразмерных композитных структур полиметилметакрилат/(Zn,Cd,Mn,Eu)S
}

\author{
(C) В.П. Смагин, А.А. Исаева
}

Алтайский государственный университет, 656049 Барнаул, Россия

e-mail: smaginV@yandex.ru

Поступило в Редакцию 14 октября 2020 г.

В окончательной редакции 1 декабря 2020 r.

Принято к публикации 7 декабря 2020 г.

Реализована коллоидная технология синтеза и легирования низкоразмерных структур на основе сульфидов цинка и кадмия непосредственно в среде акрилового мономера в процессе получения оптически прозрачных композиций полиметилметакрилат/ $\mathrm{Zn}, \mathrm{Cd}, \mathrm{Mn}, \mathrm{Eu}) \mathrm{S}$. Показано, что фотолюминесценция композиций связана с системой уровней дефектов структуры частиц полупроводника, расположенных в его запрещенной зоне, формирующихся при последовательном легировании слоев $\mathrm{ZnS}$ и $\mathrm{CdS}$ ионами $\mathrm{Mn}^{2+}$ и $\mathrm{Eu}^{3+}$, и с внутризонными ${ }^{5} D_{0} \rightarrow{ }^{7} F_{1,2,4}$ переходами $4 f$-электронов ионов $\mathrm{Eu}^{3+}$. Возбуждение фотолюминесценции происходит в результате перехода электронов из валентной зоны полупроводника на уровни дефектов его структуры и частичного переноса энергии на возбужденные уровни энергии ионов $\mathrm{Eu}^{3+}$.

Ключевые слова: полупроводники, низкоразмерные структуры, сульфид цинка, сульфид кадмия, легирование, ионы металлов, европий, фотолюминесценция, полиметилметакрилат, композиции.

DOI: $10.21883 /$ JTF.2021.05.50693.291-20

\section{Введение}

Внимание исследователей привлекают низкоразмерные структуры полупроводников групп II-VI, IV-VI, III-V [1-4]. Среди них значимое место занимают сульфиды цинка и кадмия. Люминесценцию $\mathrm{CdS}$ преимущественно связывают с дефектностью поверхности кристаллов [1]. В спектре она представлена широкой полосой с максимумом > $580 \mathrm{~nm}$. Полосы люминесценции $\mathrm{ZnS}$ смещены в синюю область. Их связывают с межзонным переходом электронов в кристаллах „чистого“ $\mathrm{ZnS}$ [5] и рекомбинационными процессами на энергетических уровнях дефектов в объеме кристаллов [6-8]. На спектр люминесценции оказывают влияние примеси, легирование $\left(\mathrm{Cu}^{2+}, \mathrm{Ag}^{+}, \mathrm{Mn}^{2+}, \mathrm{Pb}^{2+}\right)$, структура поверхности частиц и другие факторы.

Легирование халькогенидов цинка и кадмия ионами $\mathrm{Mn}^{2+}$ позволяет получать эффективные электро- и фотолюминофоры [5]. В спектре люминесценции кристаллов $\mathrm{ZnS}: \mathrm{Mn}^{2+}$ кроме полос рекомбинационного излучения в „голубой“ $(440-465 \mathrm{~nm})$, „зеленой“6 $(530 \mathrm{~nm})$, красной и ИК (620-800 nm) спектральных областях наблюдается полоса „марганцевого“ излучения (520-620 nm) [9-12]. Оно связано с переносом энергии полупроводниковой матрицы на возбужденные уровни ионов $\mathrm{Mn}^{2+}$ и ${ }^{4} T_{1} \rightarrow{ }^{6} A_{1}$ переходом электронов при возвращении в основное состояние.

В композициях $\mathrm{CdS}: \mathrm{Mn}^{2+}$ возбуждаются „марганцевые центры, локализованные на поверхности нанокристаллов $\mathrm{CdS}[13,14]$. Композиции с наночастицами $(\mathrm{Cd}, \mathrm{Mn}) \mathrm{S}$, синтезированные совместным осаждением сульфидов, люминесцируют в области $600 \mathrm{~nm}$. С уве- личением концентрации ионов $\mathrm{Mn}^{2+}$ на поверхности частиц образуется защитный слой $\mathrm{MnS}$, который тушит люминесценцию [15].

Уникальные оптические свойства лантаноидов делают их непременными компонентами многих преобразующих излучение композиций. Их применяют в сочетании с неорганическими полупроводниками [10,16-18]. В спектрах лантаноидсодержащих полупроводниковых структур наблюдаются полосы рекомбинационной и внутризонной люминесценции. Она связана с дефектами кристаллической структуры полупроводниковых кристаллов и эмиссионными переходами $4 f$-электронов между уровнями энергии ионов $\mathrm{Ln}^{3+}$. Увеличение интенсивности люминесценции лантаноидов происходит в результате сенсибилизационного переноса энергии полупроводниковой матрицы на их уровни энергии.

Для улучшения оптических свойств наночастиц применяются технологии нанесения дополнительного слоя полупроводника на поверхность сформированного ядра. В частицах ,ядро/оболочка“ оболочка выполняет защитную функцию, „сглаживает“ дефекты поверхности ядра, предотвращает безызлучательные потери энергии. В результате улучшаются оптические, электрические, магнитные свойства, стабильность и дисперсность частиц [2,19-22].

Многослойные КТ (МКТ), содержащие два и более слоя, нанесенных на ядро, обладают высоким квантовым выходом люминесценции с увеличенным временем жизни возбужденных состояний. Кроме того, они меньше подвержены фотоокислению, для них характерно улучшение структурных свойств [2,3,23-26]. Большинство из них синтезированы методами ионного наслаивания на 
подложке $[27,28]$ или химического осаждения в водной или органической среде $[26,29-34]$. В качестве сульфидизатора применяются сероводород, сульфид натрия, элементная сера, сераорганические соединения.

Одним из способов синтеза КТ и их структур является коллоидный синтез [35-38]. В водной среде синтез осложнен гидролизом. В органических средах возрастает вероятность агрегирования частиц [37,38]. Для стабилизации коллоидных растворов КТ применяются поверхностно-активные вещества $[9,14]$. Стабилизирующим является „зарядовый“ фактор [32]. Еще один способ стабилизации связан с внедрением КТ и их структур в полимерные матрицы. Предварительно синтезированные КТ помещают в раствор полимера и проводят отверждение $[39,40]$ или синтезируют непосредственно в процессе полимеризации мономера $[15,38]$. Во втором случае светопропускание акриловых композиций полимер/полупроводник при длинах волн $>450 \mathrm{~nm}$ достигает 90-92\% при толщине поглощающего слоя до $5 \mathrm{~mm}$.

Исследования, посвященные разработке технологий синтеза, изучению физико-химических свойств и структуры МКТ, синтезированных и послойно легированных in situ в процессе формирования оптически прозрачных полимерных композиций, ограничены $[15,37,38]$. В то же время такие композиции могут найти применение в электронных устройствах, преобразующих электромагнитное излучение, например, в качестве полимерных сенсоров, светодиодов, в генерирующих устройствах. Введение ионов $\mathrm{Mn}^{2+}$ оказывает влияние на магнитные свойства композиций $[11,12]$. Отличительными свойствами рассматриваемых акрилатных композиций являются сочетание широкополосной люминесценции полупроводниковых структур и узкополосной люминесценции изолированных в объеме кристаллов лантаноидов, находящихся в полимерной матрице. Включение структур в акрилатную матрицу обеспечивает единство композиции и высокую прозрачность в видимой и ближней ИК области спектра. Технологии переработки полиакрилатов позволяют изготавливать композиции в виде пленок, а также объемных изделий различной формы и размера.

Исходя из этого, цель настоящей работы состояла в изучении фотолюминесцентных свойств низкоразмерных частиц на основе сульфидов цинка, кадмия, марганца и европия в полиакрилатной матрице, синтезированных in situ при различной последовательности введения предшественников полупроводниковых (CdS, $\mathrm{ZnS})$ и легирующего $\left(\mathrm{Mn}^{2+}, \mathrm{Eu}^{3+}\right)$ компонентов в полимеризующуюся реакционную смесь.

\section{1. Характеристика объектов исследования и методики эксперимента}

Квантовые точки $(\mathrm{Zn}, \mathrm{Cd}) \mathrm{S}, \quad(\mathrm{Zn}, \mathrm{Cd}, \mathrm{Mn}) \mathrm{S} \quad$ и $(\mathrm{Zn}, \mathrm{Cd}, \mathrm{Mn}, \mathrm{Eu}) \mathrm{S}$ синтезированы по методике [41] разложением тиоцетамидных комплексов трифторацетатов цинка, кадмия, марганца и европия в среде метилметакрилата (ММА) при нагревании и далее при его полимеризации. Предшественники сульфидов матрицы $((\mathrm{Zn}, \mathrm{Cd}) \mathrm{S})$ вносили в реакционную смесь последовательно при нагревании: соль цинка и тиоацетамид (нагревание при температуре $60-70^{\circ} \mathrm{C}$ в течение $20 \mathrm{~min}$ ), далее соль кадмия и тиоацетамид (нагревание при тех же условиях) далее снова соль цинка и тиоацетамид, далее нагревание. Об образовании сульфидов судили по появлению окраски и опалесценции растворов. Легированные составы синтезированы по аналогичной схеме. Соль марганца вводили на первой и третьей стадии, одновременно с солью цинка. Соль европия на второй стадии, одновременно с солью кадмия, и на первой стадии, одновременно с солью цинка. Схематично, отражая последовательность введения компонентов в реакционную смесь, образовавшиеся в процессе синтеза продукты можно представить следующими формулами: Z ZnS/CdS/ZnS, (Zn,Mn)S/CdS/(Zn,Mn)S, $(\mathrm{Zn}, \mathrm{Mn}) \mathrm{S} /(\mathrm{Cd}, \mathrm{Eu}) \mathrm{S} / \mathrm{ZnS}$ и $(\mathrm{Zn}, \mathrm{Eu}) \mathrm{S} / \mathrm{CdS} /(\mathrm{Zn}, \mathrm{Mn}) \mathrm{S}$. Выбор последовательности введения компонентов основывался на ширине запрещенной зоны сульфидов цинка и кадмия. Выбор стадии введения легирующих компонентов связан с намерениями внедрить ионы $\mathrm{Eu}^{3+}$ в объем кристаллов ядра и оболочку. Концентрации трифторацетатов кадмия и цинка на каждой стадии внесения в реакционную смесь были равны по $3.0 \cdot 10^{-3} \mathrm{~mol} / \mathrm{L}$. Концентрация тиоацетамида была эквивалентна концентрациям ионов цинка и кадмия. Концентрация соли марганца в каждой порции составляла $5.0 \cdot 10^{-4} \mathrm{~mol} / \mathrm{L}$, концентрации соли европия $-1.0 \cdot 10^{-3} \mathrm{~mol} / \mathrm{L}$. Объем реакционной смеси во всех случаях был равен $10 \mathrm{ml}$. Опираясь на спектральные данные и результаты просвечивающей электронной микроскопии [37,38], можно предположить, что диаметр частиц в полимерной матрице не превышает $10 \mathrm{~nm}$. С учетом выбранных концентраций веществ в исходных реакционных смесях и размера синтезированных структур, их концентрация в полимерной композиции оценивается порядком величины $10^{14}-10^{15} \mathrm{~cm}^{-3}$.

Полимеризация коллоидных растворов была проведена аналогично [41] в присутствии перекиси бензоила при температуре $60-70^{\circ} \mathrm{C}$ в течение $24 \mathrm{~h}$. В результате синтезированы полимерные „стекла“ с различной структурной организацией частиц $(\mathrm{Zn}, \mathrm{Cd}, \mathrm{Mn}, \mathrm{Eu}) \mathrm{S}$, которые схематично можно обозначить следующими формулами ПММА/[ZnS/CdS/ZnS], ПMМA/[(Zn,Mn)S/ $\mathrm{CdS} /(\mathrm{Zn}, \mathrm{Mn}) \mathrm{S}], \quad \Pi \mathrm{MMA} /[(\mathrm{Zn}, \mathrm{Mn}) \mathrm{S} /(\mathrm{Cd}, \mathrm{Eu}) \mathrm{S} / \mathrm{ZnS}] \quad$ и ПММА $/[(\mathrm{Zn}, \mathrm{Eu}) \mathrm{S} / \mathrm{CdS} /(\mathrm{Zn}, \mathrm{Mn}) \mathrm{S}], \quad$ где ПММА полиметилметакрилат. Светопропускание композиций в области длин волн $>450 \mathrm{~nm}$ достигает $92 \%(5 \mathrm{~mm})$. Окраска „стекол“ близка к окраске полимеризуемых растворов. Изменение тона окраски со светлозеленого на светло-коричневые связано с различным распределением ионов $\mathrm{Cd}^{2+}$ и $\mathrm{Mn}^{2+}$ в кристаллических структурах сульфидов кадмия и цинка.

Спектры поглощения, фотолюминесценции и возбуждения фотолюминесценции композиций ПММА/ 
$(\mathrm{Zn}, \mathrm{Cd}, \mathrm{Mn}, \mathrm{Eu}) \mathrm{S}$ зарегистрировали при комнатной температуре на спектрофлуориметре Shimadzu RF-5301PC по методике [38].

\section{2. Результаты эксперимента и их обсуждение}

Полиметилметакрилат пропускает излучение с длинами волн > $320 \mathrm{~nm}$ (рис. 1, спектр 1). В области $>450 \mathrm{~nm}$ при толщине образцов $<5 \mathrm{~mm}$ пропускание превышает $90 \%$. В тонких слоях оно сопоставимо с пропусканием оптического силикатного стекла. В спектрах поглощения образцов ПММА/(Zn,Cd,Mn,Eu)S, зарегистрированных относительно пластин ПММА сопоставимой толщины, присутствует сложная полоса, связанная с наноразмерными частицами сульфидов цинка и кадмия [37,38,42]. В спектрах объемного $\mathrm{ZnS}$ край полосы поглощения для ширины запрещенной зоны $3.68 \mathrm{eV}(300 \mathrm{~K})$ находится в области $340 \mathrm{~nm}$. Для $\mathrm{CdS}$ для $2.42 \mathrm{eV}(300 \mathrm{~K})$ - в области $510 \mathrm{~nm}$. В наночастицах он гипсохромно смещается. Например, для частиц диаметром $<5 \mathrm{~nm}$ смещение края полосы поглощения происходит в область $320 \mathrm{~nm}$ $(\mathrm{ZnS})$ и $495 \mathrm{~nm}(\mathrm{CdS})[37,38,42]$. В спектре поглощения композиции ПММА/[ZnS/CdS/ZnS] (рис. 1, спектр 2) проявляется аддитивная полоса поглощения. В ее составе можно выделить четыре компоненты с максимумами в области 320, 370, 400 и $440 \mathrm{~nm}$. Коротковолновая компонента полосы $(320 \mathrm{~nm})$ связана с электронными переходами из валентной зоны в зону проводимости внешнего слоя сульфида цинка. Полоса с максимумом в области $370 \mathrm{~nm}$ относится к переходам электронов из валентной зоны на уровни дефектов структуры $\mathrm{ZnS}$. Она также преимущественно связана с процессами, протекающими во внешнем слое сульфида цинка. Длинноволновые полосы появляются в результате электронных переходов в $\mathrm{CdS}$. Также можно предположить наличие в длинноволновой области вклада поглощения ядра $\mathrm{ZnS}$. Более низкая интенсивность данных полос связана с экранированием внутренних слоев внешним слоем $\mathrm{ZnS}$ и меньшей шириной запрещенной зоны $\mathrm{CdS}$, ограничивающего прохождение внешнего излучения к ядру.

При легировании слоев $\mathrm{ZnS} / \mathrm{CdS} / \mathrm{ZnS}$ ионами $\mathrm{Mn}^{2+}$ и $\mathrm{Eu}^{3+}$ наблюдается гипсохромное смещение края полос поглощения спектральных кривых и уменьшение интенсивности длинноволновых компонент (рис. 1, спектры 3-5). Спектр композиции ПММА/[(Zn,Mn)S/ $\mathrm{CdS} /(\mathrm{Zn}, \mathrm{Mn}) \mathrm{S}]$ (рис. 1, спектр 3) воспроизводит спектр композиции не легированных сульфидов (рис. 1, спектр 2). Гипсохромное смещение аддитивного максимума $(370 \mathrm{~nm} \rightarrow 330 \mathrm{~nm})$ можно связать с разрушением системы собственных дефектов в структуре $\mathrm{ZnS}$ $(370 \mathrm{~nm})$ в результате внедрения в нее ионов $\mathrm{Mn}^{2+} \mathrm{c}$ образованием дефектов нового вида, образованных с участием ионов $\mathrm{Mn}^{2+}$. Некоторое уменьшение интенсивности длинноволновых компонент полосы связываем

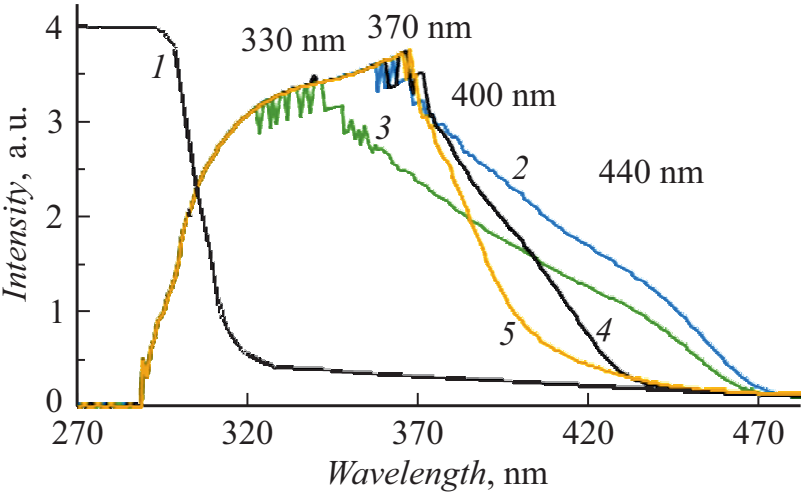

Рис. 1. Спектры поглощения ПММА (1) и композиций ПMМА/(Zn,Cd,Mn,Eu)S: ПMМА/[ZnS/CdS/ZnS] (2), ПMМА/ $[(\mathrm{Zn}, \mathrm{Mn}) \mathrm{S} / \mathrm{CdS} /(\mathrm{Zn}, \mathrm{Mn}) \mathrm{S}] \quad$ (3), ПMMA/[(Zn,Mn $) \mathrm{S} /(\mathrm{Cd}, \mathrm{Eu}) \mathrm{S} /$ $\mathrm{ZnS}](4), \Pi \mathrm{MMA} /[(\mathrm{Zn}, \mathrm{Eu}) \mathrm{S} / \mathrm{CdS} /(\mathrm{Zn}, \mathrm{Mn}) \mathrm{S}](5)$.

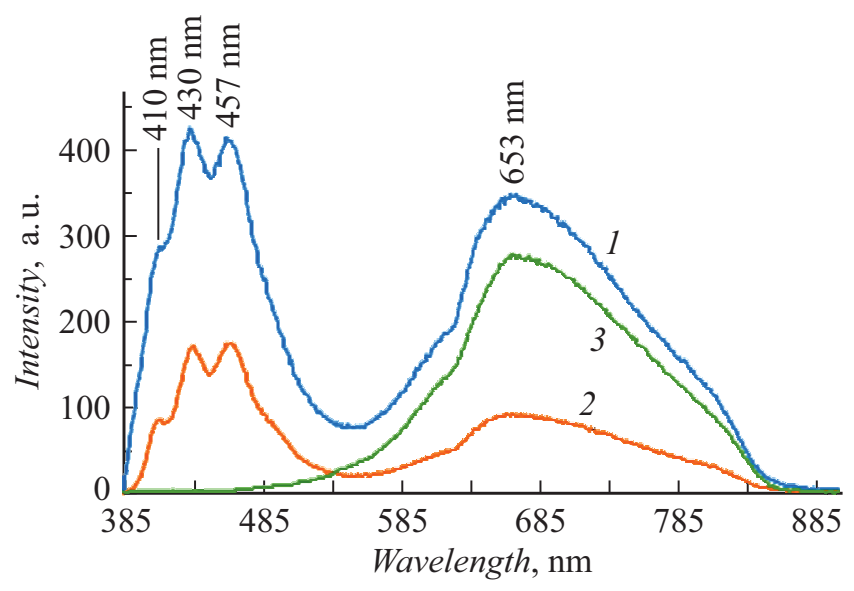

Pис. 2. Спектры люминесценции композиции ПММА/ $[(\mathrm{Zn}, \mathrm{Mn}) \mathrm{S} / \mathrm{CdS} /(\mathrm{Zn}, \mathrm{Mn}) \mathrm{S}]$ при возбуждении излучением с длинами волн (ширина щелей монохроматора), nm: $1-330$ (5-5), $2-370(3-3), 3-437(3-3)$.

с формированием фазы $\mathrm{MnS}$, препятствующего проникновению излучения во внутренние слои структуры.

В спектре композиции ПММА/[(Zn,Mn $) \mathrm{S} /(\mathrm{Cd}, \mathrm{Eu}) \mathrm{S} /$ $\mathrm{ZnS}$ ] (рис. 1, спектр 4) восстанавливается спектральная картина в области $<400 \mathrm{~nm}$, связанная с не легированным внешнем слоем $\mathrm{ZnS}$. Однако в результате легирования $\mathrm{CdS}$ ионами $\mathrm{Eu}^{3+}$, практически полностью исчезает длинноволновая компонента полосы поглощения, связанная с дефектностью CdS. Данный эффект также проявляется в спектре композиции ПMМА/[(Zn,Eu)S/CdS/(Zn,Mn)S] (рис. 1, спектр 5) при легировании ядра ионами $\mathrm{Eu}^{3+}$. Это можно считать одним из косвенных подтверждением поглощения в данной области, связанного с дефектами внутреннего слоя $\mathrm{ZnS}$, поток излучения к которому ограничен узкозонным $\mathrm{CdS}$.

В спектре фотолюминесценции композиции ПММА/ $[(\mathrm{Zn}, \mathrm{Mn}) \mathrm{S} / \mathrm{CdS} /(\mathrm{Zn}, \mathrm{Mn}) \mathrm{S}]$, зарегистрированном при возбуждении излучением с длинами волн 330, 370 и $445 \mathrm{~nm}$, 


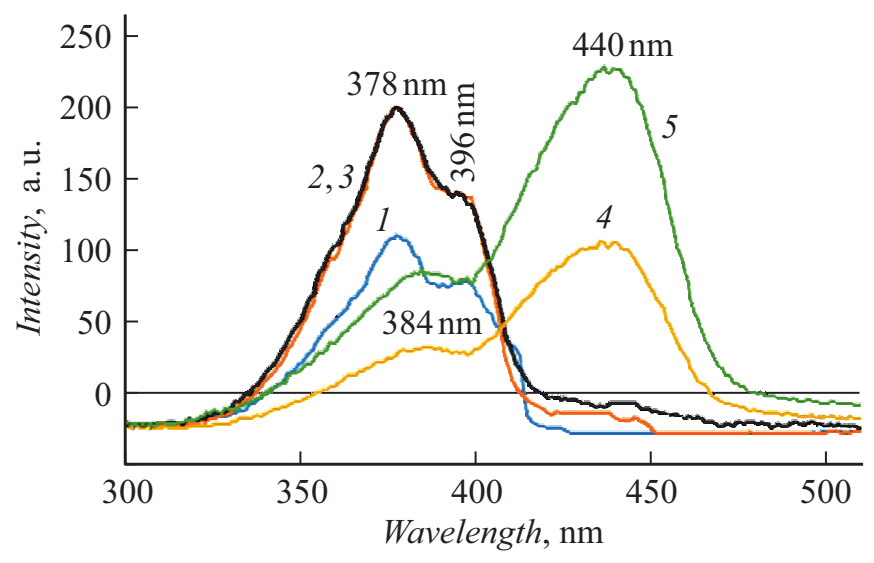

Рис. 3. Спектры возбуждения люминесценции композиции ПММА/[(Zn,Mn)S/CdS/(Zn,Mn)S] для люминесценции с длинами волн, nm: 408 (1), 430 (2), 460 (3), 615 (4), 650 (5).

наблюдаются две группы структурированных полос в областях $380-540 \mathrm{~nm}$ и $530-840 \mathrm{~nm}$ с максимумами $410,430,460 \mathrm{~nm}$ первой полосы, 620, 653 и $806 \mathrm{~nm}$ второй полосы (рис. 2, спектры $1-3$ ). В отличие от спектров фотолюминесценции композиций ПММA/ZnS, ПMМА/CdS $[41,43,44]$ и ПМMA/(ZnS/CdS/ZnS) $[41,45]$ полосы структурированы. Компоненты коротковолновой полосы связаны с люминесценцией собственных дефектов в структуре $\mathrm{ZnS}$, а также дефектов, которые создают ионы марганца. Длинноволновую полосу люминесценции дают дефекты в структуре CdS. Можно предположить, что преимущественно они располагаются в пограничной области $\mathrm{CdS} / \mathrm{ZnS}$. С увеличением длины волны возбуждающего излучения интенсивности полос перераспределяются (рис. 2, спектры 1-3). Интенсивность длинноволновой полосы увеличивается (рис. 2, спектр 1 , зарегистрирован при ширине щелей монохроматора 5-5). Интенсивность коротковолновой полосы уменьшается. При возбуждении излучением с длиной волны $445 \mathrm{~nm}$ коротковолновая полоса исчезает. Этот результат соотносится с данными отнесения полос в спектрах поглощения композиций (рис. 1).

В спектрах возбуждения люминесценции данной композиции, зарегистрированных для люминесценции с длинами волн в диапазоне $408-650 \mathrm{~nm}$ также зарегистрировано две группы сложных полос в диапазонах $340-410 \mathrm{~nm}$ и $390-470 \mathrm{~nm}$ (рис. 3 , спектры $1-5$ ). С увеличением длины волны люминесценции их структура постепенно исчезает. Интенсивность полос перераспределяется. Отсутствие в спектре полосы при длинах волн $<350 \mathrm{~nm}$ указывает на ограничение возбуждения люминесценции в результате непосредственно межзонного перехода в $\mathrm{ZnS}$ с последующим захватом электронов дефектами структуры кристалла с последующей рекомбинацией. Наличие полосы $340-410 \mathrm{~nm}$ подтверждает протекание процесса возбуждения люминесценции $\mathrm{ZnS}$ в результате переходов электронов из валентной зоны на уровни энергии дефектов в структуре $\mathrm{ZnS}$. Длинно- волновая полоса в спектре $(390-480 \mathrm{~nm})$ соответствует возбуждению люминесценции CdS. Наличие коротковолновой компоненты в области $300-420 \mathrm{~nm}$ в спектре возбуждения люминесценции, зарегистрированном для люминесценции с длинами волн 615 и $650 \mathrm{~nm}$ указывает на перенос энергии возбуждения с уровней дефектов в структуре $\mathrm{ZnS}$ на уровни дефектов в структуре $\mathrm{CdS}$ в пограничных областях слоев. Наличие интенсивной полосы возбуждения в области $400-500 \mathrm{~nm}$, перекрывающейся с полосой люминесценции $\mathrm{ZnS}$, создает условия перепоглощения люминесцентного излучения слоя $\mathrm{ZnS}$ сульфидом кадмия.

На рис. 4 приведены спектры фотолюминесценции композиции ПММA/[( $\mathrm{Zn}, \mathrm{Mn}) \mathrm{S} /(\mathrm{Cd}, \mathrm{Eu}) \mathrm{S} / \mathrm{ZnS}]$ для возбуждения излучением с длинами волн в диапазоне $320-420 \mathrm{~nm}$. Интенсивность полосы фотолюминесценции, связанной с $\mathrm{ZnS}$, увеличивается при увеличении длины волны возбуждающего излучения до $400 \mathrm{~nm}$ (рис. 4, спектр 1, щели монохроматора 5-5). При возбуждении излучением с длиной волны $420 \mathrm{~nm}$ интенсивность полосы уменьшается. По мере увеличения длины волны возбуждающего излучения структуpa полосы люминесценции $\mathrm{ZnS}$ исчезает. Это объясняется изменением системы дефектов, включенных в процесс рекомбинации. Полоса люминесценции (рис. 4, спектр 5), зарегистрированная при возбуждении излучением с длиной волны $420 \mathrm{~nm}$, связана с дефектами, которые образуют ионы $\mathrm{Mn}^{2+}$ в структуре $\mathrm{ZnS}$. Кроме того, в спектрах (рис. 4) исчезает длинноволновая полоса, связанная с фотолюминесценцией $\mathrm{CdS}$. Это происходит в результате внедрения в его структуру ионов $\mathrm{Eu}^{3+}$ и выстраиванием собственной системы уровней, которую они формируют в запрещенной зоне полупроводника. В спектре зарегистрированы собственные полосы люминесценции ионов $\mathrm{Eu}^{3+}$, связанные с ${ }^{5} D_{0} \rightarrow{ }^{7} F_{1,2,4}$ переходами $4 f$-электронов, с максимумами при 592 , 615 и $697 \mathrm{~nm}$. Низкая интенсивность полос объясняется невысокими коэффициентами поглощения лантаноидов и относительно низкой их концентрацией в образце.

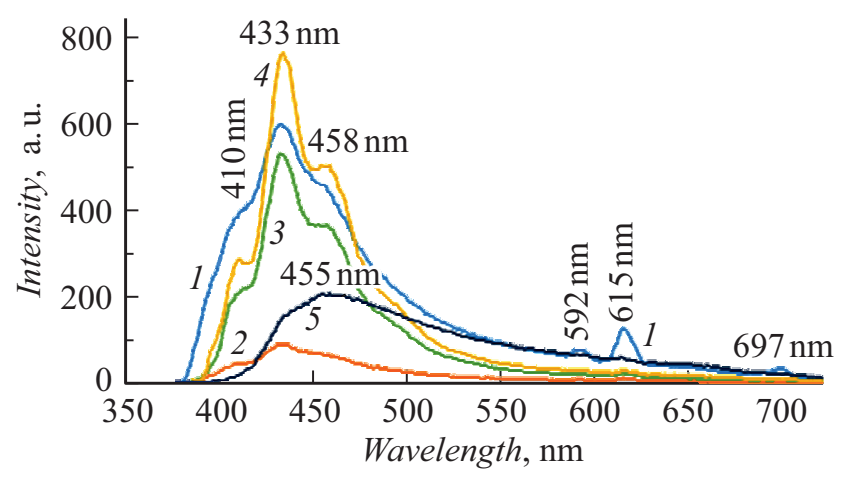

Рис. 4. Спектры люминесценции композиции ПММА/ $[(\mathrm{Zn}, \mathrm{Mn}) \mathrm{S} /(\mathrm{Cd}, \mathrm{Eu}) \mathrm{S} / \mathrm{ZnS}]$ при возбуждении излучением с длинами волн (ширина щелей монохроматора), nm: $1-320$ (5-5), $2-340(3-3), 3-370(3-3), 4-395(3-3), 5-$ $420(3-3)$. 


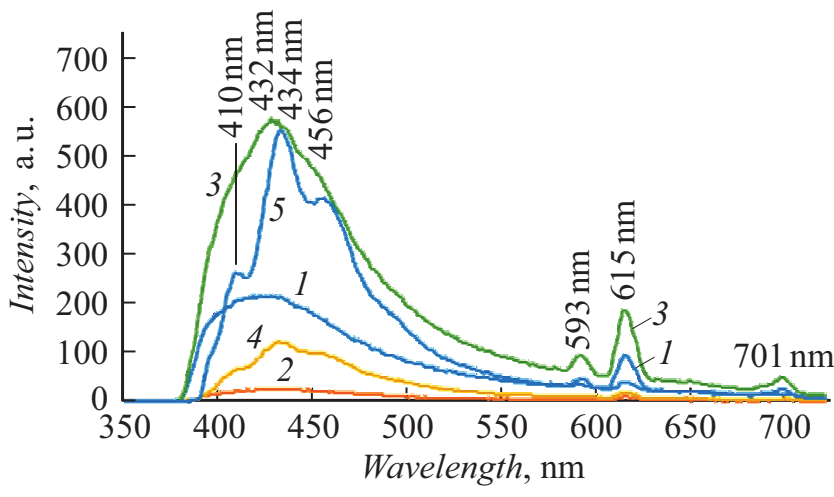

Рис. 5. Спектры люминесценции композиции ПММА/ $[(\mathrm{Zn}, \mathrm{Eu}) \mathrm{S} / \mathrm{CdS} /(\mathrm{Zn}, \mathrm{Mn}) \mathrm{S}]$ при возбуждении излучением с длинами волн (ширина щелей монохроматора), nm: $1-320$ (5-5), $2-340(3-3), 3-340$ (5-5), $4-370$ (3-3), $5-$ $395(3-3)$.

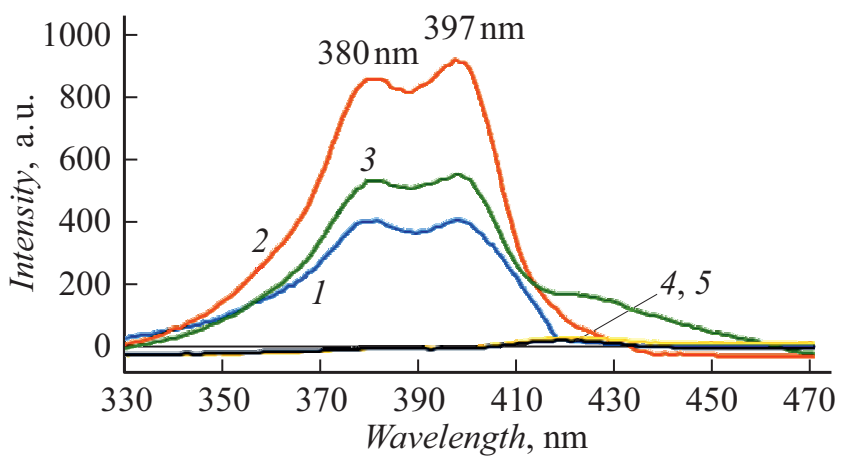

Pис. 6. Спектры возбуждения люминесценции композиции ПММА/[(Zn,Mn $) \mathrm{S} /(\mathrm{Cd}, \mathrm{Eu}) \mathrm{S} / \mathrm{ZnS}]$ для люминесценции с длинами волн, nm: 410 (1), 432 (2), 457 (3), 591 (4), 615 (5), ширина щелей монохроматора $3-3$.

B спектрах люминесценции композиции ПММА/ $(\mathrm{Zn}, \mathrm{Eu}) \mathrm{S} / \mathrm{CdS} /(\mathrm{Zn}, \mathrm{Mn}) \mathrm{S}$ (рис. 5) отмечено общее уменьшение пиковой интенсивности полос, связанных с ZnS. Структура полосы, зарегистрированная при возбуждении излучением с длиной волны $320 \mathrm{~nm}$, исчезает (рис. 4, спектр 1 и рис. 5, спектр 1), в спектре преимущественно наблюдается ее „сглаженная“ коротковолновая компонента. Кроме того, наблюдается уширение полосы (возбуждение излучением с длиной волны $395 \mathrm{~nm}$, рис. 4 , спектр 4 и рис. 5 , спектр 5) с потерей пиковой интенсивности и размыванием структуры. Интенсивность собственных полос люминесценции ионов $\mathrm{Eu}^{3+}$ увеличивается при увеличении длины волны возбуждающего излучения (рис. 5, спектры 1 и 3, щели монохроматора 5-5). Наблюдающиеся изменения связываем с изменением состава слоев, внедрением ионов $\mathrm{Eu}^{3+}$ в структуру $\mathrm{ZnS}$, ограничением доли возбуждающего излучения внешними слоями. Исчезновение полосы люминесценции $\mathrm{CdS}-$ с изменением структуры его пограничных слоев, ответственных за люминесценцию, при легировании внутреннего и внешнего слоя $\mathrm{ZnS}$.

$\mathrm{B}$ спектрах возбуждения люминесценции композиции ПММА/[(Zn,Mn)S/(Cd,Eu)S/ZnS], зарегистрированных для люминесценции с длинами волн 410, 432, 457, 591 и $615 \mathrm{~nm}$, наблюдается сложная полоса в диапазоне $350-450 \mathrm{~nm}$ с максимумами 380 и $397 \mathrm{~nm}$ (рис. 6). Положение полосы позволяет связать люминесценцию данной композиции с переходом электронов из валентной зоны $\mathrm{ZnS}$ на уровни дефектов его структуры и далее с рекомбинацией на одном из дефектных уровней с выделением квантов излучения. Собственные полосы ионов $\mathrm{Mn}^{2+}$ и $\mathrm{Eu}^{3+}$ в спектрах не зарегистрированы. Это связано с их ограниченной концентрацией в образцах. Участие в люминесценции ионов $\mathrm{Mn}^{2+}$ заключается в формировании дефектов в структуре $\mathrm{ZnS}$. Возбуждение собственной люминесценции ионов $\mathrm{Eu}^{3+}$ преимущественно происходит в результате переноса энергии на их возбужденные уровни энергии с уровней дефектов в структуре полупроводников. Наличие длинноволнового

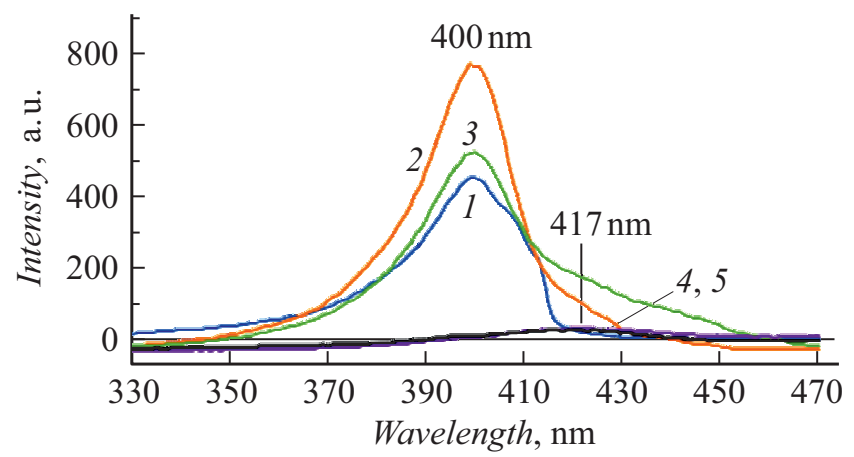

Рис. 7. Спектры возбуждения люминесценции композиции ПММА/[(Zn,Eu)S/CdS/(Zn,Mn)S $]$ для люминесценции с длинами волн, nm: 410 (1), 434 (2), 455 (3), 592 (4), 615 (5), ширина щелей монохроматора 3-3.

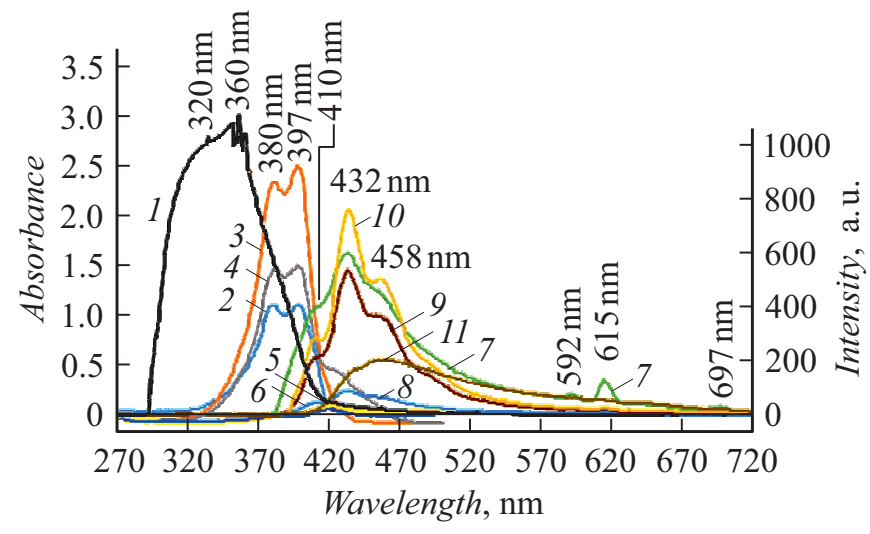

Рис. 8. Спектры композиции ПММА/[(Zn,Mn)S/ $(\mathrm{Cd}, \mathrm{Eu}) \mathrm{S} / \mathrm{ZnS}]: \quad 1-$ поглощения; 2-6 - возбуждения люминесценции для люминесценции с длинами волн, $\mathrm{nm}$ : 410 (2), 430 (3), 457 (4), 590 (5), 615 (6); 7-11 люминесценции при возбуждении излучением с длинами волн, nm: 320 (7), 340 (8), 370 (9), 397 (10), 420 (11). 
плеча полосы возбуждения люминесценции, зарегистрированной для длинноволновой компоненты люминесценции $\mathrm{ZnS}$ (457 nm) (рис. 6, спектр 3), подтверждает высказанное ранее предположение о наличии вклада в данную полосу люминесценции внутреннего слоя $\mathrm{ZnS}$.

Изменение последовательности легирования в процессе синтеза вносит ряд особенностей в спектры возбуждения (рис. 7). В спектре композиции ПMМА/(Zn,Eu)S/CdS/(Zn,Mn)S (рис. 7) в отличие от спектров, приведенных на рис. 6, коротковолновая компонента полосы возбуждения отсутствует. Это связано с введением во внешний слой $\mathrm{ZnS}$ ионов $\mathrm{Mn}^{2+}$, которые формируют собственную систему дефектов в структуре $\mathrm{ZnS}$, ответственных за процессы поглощения и рекомбинации.

На рис. 8 приведены спектры поглощения 1, возбуждения люминесценции 2-6 и люминесценции 7-11 композиции на одном координатном поле. Это позволяет более наглядно соотнести энергетические потоки в композиции и отметить ту часть поглощенной структурами $[(\mathrm{Zn}, \mathrm{Mn}) \mathrm{S} /(\mathrm{Cd}, \mathrm{Eu}) \mathrm{S} / \mathrm{ZnS}]$ энергии, которая оказывается преобразованной в люминесцентное излучение.

\section{Заключение}

Методом коллоидного синтеза в процессе полимеризации акрилового мономера получены оптически прозрачные полимерные композиции, содержащие в своем составе низкоразмерные структуры на основе сульфидов цинка и кадмия, послойно легированные ионами $\mathrm{Mn}^{2+}$ и $\mathrm{Eu}^{3+}$. Показано, что возбуждение люминесценции композиций происходит в результате переходов электронов из валентной зоны полупроводников на уровни структурных дефектов, а также частичном переносе ее с этих уровней на собственные возбужденные уровни энергии ионов $\mathrm{Eu}^{3+}$. Фотолюминесценция композиций возникает при рекомбинации электрон-дырочных пар с выделением кванта энергии видимого диапазона, а также при ${ }^{5} D_{0} \rightarrow{ }^{7} F_{1,2,4}$ переходах $4 f$-электронов ионов $\mathrm{Eu}^{3+}$. Спектры возбуждения и фотолюминесценции зависят от структуры образующихся дефектов, формируемой при введении легирующих ионов на соответствующей стадии синтеза композиций.

\section{Благодарности}

Работа выполнена с использованием научного оборудования межрегионального центра коллективного пользования НИ „Томский государственный университет“.

\section{Конфликт интересов}

Авторы заявляют, что у них нет конфликта интересов.

\section{Список литературы}

[1] B.P. Chandra, V.K. Chandra, P. Jha. Solid State Phenomena, 222, 1 (2015). DOI: 10.4028/www.scientific.net/SSP.222.1

[2] A.M. El-Toni, M.A. Habila, J.P. Labis, Z.A. ALOthman, M. Alhoshan, A.A. Elzatahry, F. Zhang. Nanoscal., 8 (5), 2510 (2016). https://doi.org/10.1039/C5NR07004J

[3] E. Ramya, M.V. Rao, D.N. Rao. Physica E: Low-Dimensional Systems and Nanostructures, 107, 24 (2019). DOI: $10.1016 /$ j.physe.2018.11.010

[4] N.X. Ca, N.T. Hien, N.T. Luyen, V.T.K. Lien, L.D. Thanh, P.V. Do, N.Q. Bau, T.T. Pham. J. Alloys Compounds, 787, 823 (2019). https://doi.org/10.1016/j.jallcom.2019.02.139

[5] О.Н. Казанкин, Л.Я. Марковский, И.А. Миронов, Ф.М. Пекерман, Л.Н. Петошина Неорганические люминоборы (Изд-во Химия, Л., 1975)

[6] Т.А. Кучакова, Г.В. Весна, В.А. Макара. ФТП, 38 (11), 1316 (2004). [T.A. Kuchakova, G.V. Vesna, V.A. Makara. Semiconductors, 38 (11), 1275 (2004). DOI: $10.1134 / 1.1823058]$

[7] Ю.Ю. Бачериков, И.П. Ворона, С.В. Оптасюк, В.Е. Родионов, А.А. Стадник. ФТП, $\mathbf{3 8}(9), 1025$ (2004). [Yu.Yu. Bacherikov, I.P. Vorona, S.V. Optasyuk, V.E. Rodionov, A.A. Stadnik. Semiconductors, $38(9), 987$ (2004). DOI: 10.1134/1.1797471]

[8] Н.К. Морозова, И.А. Каретников, Д.А. Мидерос, Е.М. Гаврищук, В.Б. Иконников. ФТП, 40 (10), 1185 (2006) [N.K. Morozova, I.A. Karetnikov, D.A. Mideros, E.M. Gavrishchuk, V.B. Ikonnikov. Semiconductors, 40 (10), 1155 (2006). DOI: 10.1134/S106378260610006X]

[9] R.N. Bhargava, D. Gallagher, X. Hong, A. Nurmikko. Phys. Rev. Lett., 72, 416 (1994).

[10] J. Planelles-Aragó, B. Julián-López, E. Cordoncillo, P. Escribano, F. Pelle', B. Viana, C. Sanchez. J. Mater. Chem., 18 (43), 5193 (2008). DOI: 10.1039/b809254k

[11] Ю.Г. Галяметдинов, Д.О. Сагдеев, В.К. Воронкова, А.А. Суханов, Р.Р. Шамилов. Известия АН. Сер. хим., 67 (1), 172 (2018). [Y.G. Galyametdinov, D.O. Sagdeev, V.K. Voronkova, R.R. Shamilov, A.A. Sukhanov. Rus. Chem. Bulletin, 67 (1), 172 (2018). DOI: 10.1007/s11172-018-2055-1]

[12] Д.О. Сагдеев. Автореф. канд. дисс. (КНИИТУ, Казань, 2019).

[13] A.A. Bol, R. Van Beek, J. Ferwerda, A. Meijerink. J. Phys. Chem. Solids., 64 (2), 247 (2003). DOI: $10.1016 / \mathrm{S} 0022-3697(02) 00286-\mathrm{X}$

[14] S. Salimian, S.F. Shayesteh. J. Supercond. Nov. Magn., 25 (6), 2009 (2012). DOI: 10.1007/s10948-012-1549-6

[15] А.А. Исаева, В.П.Смагин. Ползуновский вестник, 2, 107 (2018). DOI: 10.25712/ASTU.2072-8921.2018.02.020

[16] P. Mukherjee, R.F. Sloan, Ch.M. Shade, D. H. Waldeck, S. Petoud. J. Phys. Chem. C., 117 (27), 14451 (2013). DOI: $10.1021 / \mathrm{jp} 404947 \mathrm{x}$

[17] Z. Liang, J. Mu, L. Han, H. Yu. J. Nanomaterials, Volume 2015. Article ID 519303. https://doi.org/10.1155/2015/519303

[18] Q. Chen, J. Song, Ch. Zhou, Q. Pang, L. Zhou. Mater. Sci. Semicond. Process., 46, 53 (2016). https://doi.org/10.1016/j.mssp.2016.02.005

[19] H. Feng, L. Tang, G. Zeng, Ya. Zhou, Ya. Deng, X. Ren, B. Song, Ch. Liang, M. Wei, J. Yu. Adv. Colloid Interface Sci., 267, 26 (2019). https://doi.org/10.1016/j.cis.2019.03.001 
[20] T.A. Esquivel-Castroa, M.C. Ibarra-Alonso, J. Oliva, A. Martínez-Luévanos. Mater. Sci. Engineer., 96, 915 (2019). https://doi.org/10.1016/j.msec.2018.11.067

[21] W. Lu, X. Guo, Yu. Luo, Q. Li, R. Zhu, H. Pang. Chem. Eng. J. 355, 208 (2019). https://doi.org/10.1016/j.cej.2018.08.132

[22] H. Zhao, F. Rosei. Chemistry, 3 (2), 229 (2017). https://doi.org/10.1016/j.chempr.2017.07.007

[23] D.V. Talapin, I. Mekis, S. Götzinger, A. Kornowski, O. Benson, H. Weller. Phys. Chem. B, 108 (49), 18826 (2004). https://doi.org/10.1021/jp046481g

[24] Y. Lu, Y.Q. Zhang, X.A. Cao. Appl. Phys. Lett., $102(2)$, 023106 (2013). https://doi.org/10.1063/1.4775678

[25] P. Melinon, S. Begin-Colin, J.L. Duvail, F. Gauffre, N.H. Boime, G. Ledoux, J. Plain, P. Reiss, F. Silly, B. Warot-Fonrose. Phys. Reports, 543, 163 (2014). http://dx.doi.org/10.1016/j.physrep.2014.05.003

[26] H. Kumar, A. Kumari, R.R. Singh. Opt. Mater., 69, 23 (2017). http://dx.doi.org/10.1016/j.optmat.2017.04.009

[27] C. Rosiles-Perez, A. Cerdán-Pasarán, S. Sidhik, D. Esparza, T. López-Luke, E. de la Rosa. Solar Energy., 174 (1), 240 (2018). https://doi.org/10.1016/j.solener.2018.08.081

[28] N.S.M. Mustakim, Ch.A. Ubani, S. Sepeai, N.A. Ludin, M.A.M. Teridi, M.A. Ibrahim. Solar Energy, 163, 256 (2018). https://doi.org/10.1016/j.solener.2018.02.003

[29] Ch.V Reddy, J. Shim, M. Cho. J. Phys. Chem. Solids. 103, 209 (2017). https://doi.org/10.1016/j.jpcs.2016.12.011

[30] W. Cao, X. Zhang, Yu. Zheng, K. Wang, H. Dai. Intern. J. Hydrogen Energy, 42 (5), 2924 (2017). https://doi.org/10.1016/j.ijhydene.2016.10.116

[31] P. Kunstman, J. Coulon, O. Kolmykov, H. Moussa, L. Balan, G. Medjahdi, J. Lulek, R. Schneider. J. Luminescence, 194, 760 (2018). https://doi.org/10.1016/j.jlumin.2017.09.047.

[32] А.А. Бирюков, Т.И. Изаак, В.А. Светличный, О.В. Бабкина Известия вуз. Физика, 49 (12), 81 (2006) [A.A. Biryukov, T.I. Izaak, V.A. Svetlichnyi, O.V. Babkina. Russ. Phys. J., 49 (12), 1354 (2006). DOI: 10.1007/s11182-006-0265-8]

[33] H. Zhao, H. Liang, F. Vidal, F. Rosei, A. Vomiero, D. Ma. J. Phys. Chem. C, 118 (35), 20585 (2014). https://doi.org/10.1021/jp503617h

[34] Т.В. Самофалова, В.Н. Семенов. Конденсированные среды и межфазные границы. 18 (2), 248 (2016).

[35] S. Muruganandam, G. Anbalagan, G. Murugadoss. Ind. J. Phys., 89 (8), 835 (2015). DOI: 10.1007/s12648-015-0650-7

[36] M. Kuzmanović, D.K. Bozanić, D. Milivojević, D.M. Culafić, S. Stanković, C. Ballesteros, J. Gonzalez-Benito. RSC Advances., 7 (84), 53422 (2017).

https://doi.org/10.1039/C7RA11011A

[37] В.П. Смагин, Д.А. Давыдов, Н.М. Унжакова, А.А. Бирюков. ЖОХ, $\mathbf{6 0}(12), 1734$ (2015). DOI: $\quad 10.7868 / \mathrm{S} 0044457 \mathrm{X} 15120247 \quad$ [V.P. Smagin, D.A. Davydov, N.M. Unzhakova, A.A. Biryukov Russ. J. Inorg. Chem., 60 (12), 1588 (2015) DOI: $10.1134 / \mathrm{S} 0036023615120244]$

[38] В.П. Смагин, А.А. Исаева, Н.С. Еремина, А.А. Бирюков. ЖПХ, 88 (6), 924 (2015). [V.P. Smagin, A.A. Isaeva, N.S. Eremina, A.A. Biryukov. Russ. J. Appl. Chem., 88 (6), 1020 (2015). DOI: 10.1134/S1070427215060208]

[39] К.Ю. Пономарева, И.Д. Кособудский, Е.В. Третьяченко, Г.Ю. Юрков. Неорган. матер., 43 (11), 1295 (2007) [K.Yu. Ponomareva, I.D. Kosobudsky, E.V. Tret'yachenko, G.Yu. Yurkov. Inorganic Materials, 43 (11), 1160 (2007) DOI: $10.1134 / \mathrm{S} 0020168507110027]$
[40] R.M. Abozaid, Z.Ž. Lazarević, I. Radović, M. Gilić, D. Šević, M.S. Rabasović, I. Radović. Opt. Mater., 92, 405 (2019). https://doi.org/10.1016/j.optmat.2019.05.012

[41] А.А. Исаева, В.П. Смагин. Журн. неорган. химии, 64 (10), 1020 (2019). DOI: 10.1134/S0044457X19100064 [A.A. Isaeva, V.P. Smagin. Russ. J. Inorg. Chem., 64 (10), 1199 (2019). DOI: 10.1134/S0036023619100061]

[42] В.П. Смагин, Н.С. Еремина, М.С. Леонов. Неорган. матер., 54 (2), 115 (2018). DOI: 10.7868/S0002337X1802001X [V.P. Smagin, N.S. Eremina, M.S. Leonov. Inorganic Materials, 54 (2), 103 (2018). DOI: 10.1134/S0020168518020139]

[43] В.П. Смагин, Н.С. Еремина, М.С. Леонов. ФТП, 52 (8), 891 (2018) DOI: 10.21883/FTP.2018.08.46214.8729 [V.P. Smagin, N.S. Eremina, M.S. Leonov. Semiconductors, 52 (8), 1022 (2018). DOI: $10.1134 / \mathrm{S} 1063782618080213$

[44] В.П. Смагин, Н.С. Еремина, А.Г. Скачков. Опт. и спектр., $124(5), 635$ (2018). DOI: $10.21883 /$ OS.2018.05.45944.292-17-17 [V.P. Smagin, N.S. Eremina, A.G. Skachkov. Opt. Spectr., $124(5), 668$ (2018). DOI: 10.1134/S0030400X1805020X]

[45] А.А. Исаева, В.П. Смагин. ФТП, 54 (12), 1321 (2020). DOI: $10.21883 /$ FTP.2020.12.50232.9475 [A.A. Isaeva, V.P. Smagin. Semiconductors, 54 (12), 1583 (2020). DOI: $10.1134 / \mathrm{S} 1063782620120106]$ 